\title{
LAZER NO CENTRO URBANO DE PRESIDENTE PRUDENTE - BREVE ANÁLISE
}

Natalia Catarine Tomé Marcondes ${ }^{1}$, Fernando Gomes Piffer ${ }^{1}$, Juliana Elaine dos Santos ${ }^{1}$, Willian Ferreira lacunas ${ }^{1}$, Yeda Ruiz Maria ${ }^{2}$

${ }^{1}$ Discentes do curso de Arquitetura e Urbanismo da Universidade do Oeste Paulista- UNOESTE. ${ }^{2}$ Docente dos cursos de arquitetura e urbanismo, engenharia ambiental e sanitária e design de interior da universidade do oeste paulista. arqdesmarcondes@gmail.com

\section{RESUMO}

O lazer tem-se tornado cada dia mais importante no cotidiano da sociedade. Os indivíduos têm-se ocupado cada dia mais de tarefas para sua subsistência e isto tem gerado maior necessidade ao ócio. Com isto, é visto que é um dever do poder público suprir as necessidades da população, criando meios para a execução de projetos que visam melhorar a qualidade de vida por meio dos espaços dedicados ao lazer. Um projeto de qualidade proporciona uma maior identidade do espaço com a comunidade e com isso aprimora o uso do espaço público voltado ao lazer. Este presente trabalho tem por objetivo ampliar o acesso ao lazer, afim de compreende-lo como um direito de todos os cidadãos. Como ponto de partida será tomado como base as problemáticas existentes nos espaços de lazer do centro de Presidente Prudente - SP, este, trará subsídios para possíveis projetos de revitalização urbana e para a implementação de uma nova política pública de lazer. A metodologia de pesquisa apresentou-se por meio de estudos bibliográfico sobre o tema proposto, de forma a dar subsídios teóricos para a compreensão, discussão, análise e modelos existente sobre espaços de lazer.

Palavras - chave: lazer, políticas públicas, espaços públicos, revitalização

\section{INTRODUÇAO}

Segundo Gomes (2003) existem duas correntes de pesquisa sobre o surgimento do lazer. Há autores que consideram que o lazer existe desde as sociedades antigas e há os que entendem o lazer como um fenômeno moderno, com origem marcada nas modernas sociedades urbanoindustriais (DUMAZEDIER, 1980; MARCELINO, 1983; MELO, 2003; MASCARENHAS, 2005).

A definição de lazer segundo MARCELINO (2001) e DUMAZEDIER (1980) é de um conjunto de ocupações as quais o indivíduo pode entregar-se de livre vontade, seja para repousar ou para entreter-se. Pode ainda ser caracterizado pela sua participação social voluntária, ou sua livre capacidade criadora após livrar-se ou desembaraçar-se das obrigações profissionais, familiares e sociais (MARCELINO, 2001; DUMAZEDIER, 1980).

Vale enfatizar que com o passar dos tempos o conceito e a importância do lazer vem se modificando conforme os presentes valores e o atual contexto sociocultural . 
Neste contexto YURGEL (1983) esclarece que nos tempos primitivos, a conquista do lazer está gravada nas pinturas das cavernas, onde era retratado por meio da pintura rupestre, a magia e os dias de caça.

MEDEIROS (1975, p. 03) demonstrando uma relação entre o surgimento do lazer e a religiosidade.

Tão imperiosa é a necessidade de dispor de algum tempo livre, que o próprio Criador, ao terminar a Sua Obra, descansou e ordenou que todos, sem distinção de classe, guardassem o sábado.

Portanto conclui Medeiros (1975) que após atendidas as necessidades de sobrevivência e cumpridas as suas obrigações, a humanidade tem se voltado para o tempo de folga, preenchendoo cada qual a sua maneira conforme seu contexto sociocultural.

Com o surgimento da indústria, o trabalho passou a ser considerado como necessidade primeira do homem, e o tempo livre como lazer é visto como um período para recuperar as forças para retornar ao trabalho (MASCARENHAS, 2005).

Para Yurgel (1983) Aristóteles sabiamente pontua que a educação tem por objetivo o uso adequado do lazer, não sendo adquirida apenas como um instrumento para o indivíduo tornar-se técnico, mas para educar-se, e, assim, ter sabedoria para aproveitar o tempo livre.

Estudos médicos comprovam a eficácia que o lazer exerce no combate a doenças com origens em estresse mental e corporal, ou seja, o lazer se faz cada dia mais necessário motivado pela estética corporal e mental humana (OLIVEIRA, 2001). Entretanto são primordiais a presença de espaços verdes e praças no contexto urbano da cidade, visto que os mesmos possuem papel estruturador dos espaços livres e de socialização aos indivíduos ( MARCELINO, 1995; SOUSA, 2005; MARIA, 2010).

Do exposto conclui-se que lazer é cultura e está diretamente relacionado à ânsia da satisfação psicológica por meio da vivência social, sendo uma necessidade cotidiana a existência social e histórica ampla, influenciando as relações socioculturais.

Consta que já houve estudos e teorias para a busca de solução das problemáticas da implantação do lazer no espaço urbano, entretanto, qualquer que seja a teoria planejada e aplicada, a mesma só obterá sucesso se houver uma colaboração dos órgãos públicos e um melhor entendimento da importância e benefícios que um espaço de lazer pode atribuir aos indivíduos (MARIA, 2010).

MARCELINO (2001) enfatiza que antes de atuar em qualquer contexto urbano com a intenção de propor soluções as questões de lazer, há a necessidade de relacionar os problemas de 
infra-estrutura urbana, áreas verdes e a distribuição da população intra urbana tendo de haver um trabalho em conjunto com os setores municipais.

Sendo assim entende-se que para a implantação de espaços é necessário que haja a interpretação das reais necessidades da população como futura usuária do local.

O presente artigo tem como objetivo geral analisar a situação atual do lazer no centro de Presidente Prudente - SP. Especificamente tem como objetivo identificar os espaços de lazer existentes, identificar suas carências e apontar modelos aplicáveis e possíveis ao centro de Presidente Prudente - SP.

A metodologia de pesquisa apresentou-se por meio de estudos bibliográfico sobre o tema proposto, de forma a dar subsídios teóricos para a compreensão, discussão, análise e modelos existente sobre espaços de lazer. Posterior aos estudos teórico teve-se a necessidade de análises in loco para caracterização do lazer no centro de Presidente Prudente-SP.

\section{LAZER NO CENTRO DE PRESIDENTE PRUDENTE-SP}

O quadrilátero central de Presidente Prudente-SP possui duas praças: Praça da Bandeira, onde estão os camelódromos; Praça 9 de Julho, onde está situada a fonte. As análises in loco, realizadas pela presente pesquisa, detecta que, como em vários outros espaços da cidade dedicados ao lazer, ambas encontram-se em estado de abandono, principalmente a Praça 9 de Julho onde vemos muitas pichações e equipamentos se deteriorando.

Situação semelhante ocorria há 15 anos, quando Araújo e Cesário (1998) fizeram suas observações através de uma pesquisa sobre a situação dos espaços de lazer em Presidente Prudente e a relação dos mesmos com a qualidade de vida da população.

Através de visitas in loco, notou-se que o estado de abandono dos espaços de lazer de Presidente Prudente, inclusive do centro, da-se pela escolha incorreta dos equipamentos inseridos nos espaços dedicados ao lazer, e, consequentemente, a falta de identidade da população.

Além destes motivos, Cesário (1998) enfatiza que o insucesso dos espaços de lazer público em Presidente Prudente - SP, se dá principalmente pela falta de atenção do poder público com a criação, reforma e construção de áreas melhores de lazer. Nota-se que cada organismo trabalha isoladamente, não tratando o lazer enquanto política pública e é evidente o desejo da população em maior atenção as áreas de lazer (ARAUJO e CESÁRIO 1998).

A partir disto, e com as análises in loco, nota-se que 15 anos mais tarde a situação dos espaços dedicados ao lazer no centro de Presidente Prudente não obteve alterações, visto que, a 
população continua não sentindo a importância de reivindicarem seus direitos de lazer de qualidade ao poder público. Fazendo com que o poder público fique indiferente às problemáticas destes espaços.

\section{CONCLUSÃO}

O lazer público é um elemento social que viabiliza a prática de valores de ordem moral e cultural da sociedade, não sendo apenas como oportunidade de recreação e sim, como oportunidade para a população de uma melhor formação de caráter moral. Sendo assim, faz-se necessário uma análise nos sistemas de espaços livres e locais de prática de lazer, a fim de buscar soluções para a formação de um sistema de lazer adequado, acessível e seguro.

Providenciar um sistema de lazer adequado no centro de Presidente Prudente, com áreas verdes e áreas livres de recreação, é um elemento indispensável para um planejamento urbano eficiente e satisfatório. Além disto, espaços de lazer de melhor qualidade no centro da cidade trariam benefícios para o valor turístico e econômico, visto que, a cidade seria classificada com melhor qualidade de vida.

É de suma importância que os projetos de revitalização, reforma ou construção de áreas de lazer tenham o envolvimento da sociedade, notando suas necessidades e aspirações. Caso contrário, o resultado sempre será espaços públicos que não são de uso público por seu conteúdo não ser concebido como tal.

Sendo assim, podemos destacar alguns exemplos de projetos de revitalização e reforma de espaços de lazer que buscaram em seu conteúdo uma maior interação da sociedade com o espaço ali inserido, evitando o estado de abandono.

O projeto de revitalização da Praça Prefeito José Luiz da Costa, em Conceição da Barra - ES, teve como principal objetivo a melhor utilização do espaço pelo público sem perder a identidade bucólica, integrando-a tanto em relação ao prédio moderno da prefeitura quanto a histórica Igreja.

No projeto houve a incorporação da Praça da Maria Fumaça das ruas laterais e frontal da Igreja, totalizando numa área total de $1500 \mathrm{~m}^{2}$, sendo o piso aplicado no mesmo nivelamento, incluindo as ruas laterais, para melhor aproveitamento de espaço. O trafego de veículos nas "antigas" ruas será permitido apenas para o acesso ás residências da área.

A Praça Maria Fumaça será convertida em um espaço artístico, gastronômico e cultural onde serão instalados boxes específicos para a gastronomia e comercialização da produção 
artesanal do município, além da construção de um palco para a realização de eventos e apresentações culturais, como a Bandinha (grupo de música tradicional barrense) e os grupos folclóricos.

Outro projeto é a Revitalização da Praça Rui Barbosa, em Belo Horizonte - MG. A região onde a praça de localiza é caracterizada como importante pólo de comércio, sendo sede de pequenas indústrias e área de grande concentração de hotéis e pensões. Com o crescimento da cidade, no ano de 1922 uma nova estação foi construída no local e em 1936, instalou-se a fonte luminosa Independência, sendo esta uma atração para os moradores e visitantes da capital.

Com o processo de modernização e urbanização de Belo Horizonte, ao longo do século XX o projeto sofreu algumas alterações. Os jardins foram reduzidos, para dar espaço a novas ruas e avenidas e as estátuas foram transferidas de local.

A reforma buscou devolver a praça a sua importância histórica para a cidade, sendo em 2005, implantado o Museu de Artes e Ofícios com o intuito de preservar a memória do trabalho e das relações sociais no Brasil.

Em 2007 houve intervenções que tiveram o objetivo de melhorar as condições de acesso à Estação Central do Trem Metropolitano, o metrô. O local ganhou pisos em placas de concreto avermelhado, instalação de dois conjuntos de fontes, postes de iluminação, além da implantação de um projeto paisagístico.

A partir de estudos de casos e análise de contexto, é possível estruturar novas diretrizes para a elaboração de um projeto de espaços de lazer de qualidade, sendo que essas diretrizes não devem abordar somente a melhoria de equipamentos e infra estrutura, mas devem visar melhorias na política de lazer que envolve a sociedade.

A revitalização deve ser projetada no sentido de aumentar a eficiência do espaço de lazer e, consequentemente, um novo impulso para a comunidade diante de uma melhor qualidade de vida.

Sendo assim, um projeto de qualidade proporciona uma maior identidade do espaço com a comunidade e com isso aprimora o uso do espaço público voltado ao lazer. 


\section{REFERENCIAS}

ARAUJO, M. M. O; CESÁRIO, S. R. O Lazer em Presidente Prudente: Reflexoes sobre a Qualidade de Vida. Monografia de Conclusão de Curso de Especialização em Planejamento e Gestão Municipal, pós graduação lato-sensu) Presidente Prudente: UNESP/FCT, 1998.

DUMAZEDIER, J. Valores e Conteúdos Culturais do Lazer. São Paulo: SESC, 1980.

GOMES, C. L. Significados de recreação e lazer no Brasil: Reflexões a partir da análise de experiências institucionais (1926-1964). Tese de doutorado em Educação: Universidade Federal de Minas Gerais, 2003.

MARCELINO, N.C. Lazer e Esportes: políticas públicas. 2.ed. Campinas: Autores Associados, 2001. Lazer e Humanização. 3ed. Campinas: Papirus, 1995.

MARIA, Y. R. A compreensão do Lazer no Planejamento Urbano de Narandiba -SP. Presidente Prudente: Universidade do Oeste Paulista, 2010.

MASCARENHAS, F. Entre o ócio e o negócio: teses acerca da anatomia do lazer. Tese de doutorado. Faculdade de Educação Física. Universidade Estadual de Campinas. Campinas, 2005

MEDEIROS. E. B. O lazer no Planejamento Urbano. 2.ed. Rio de Janeiro: Editora FGV, 1975.

MELO, V. A. de, ALVES JUNIOR, E. D. Introdução ao lazer. Barueri, SP: Manole, 2003.

OLEIAS, V. J. Conceito de Lazer. Santa Catarina: Universidade Federal de Santa Catarina, 2013.

OLIVEIRA, G. C. Projeto Pilão D’Água: Um espaço de lazer. Marília: Universidade de Marília, 2001.

SOUSA, R.O. de S. A praça como lugar da diversidade Cultural. Barra do Bugres: Universidade do Estado de Mato Grosso, 2005.

YURGEL, M. Urbanismo e Lazer. São Paulo: Nobel, 1983. 